\title{
A COLABORAÇÃO COMO MOVIMENTO ÉTICO-POÉTICO A CAMINHO DO “NOVO" NAS AULAS DE LITERATURA
}

Rodolfo Meissner Rolando*

RESUMO: Os estudos de Cereja (2005), Cosson $(2006,2014)$ Paulino e Cosson (2009) e Zilmerman e Rösing (2009), entre outros pesquisadores, têm indicado uma crise no ensino de literatura. Nesse sentido, um dos principais problemas decorrentes dessa crise - ainda pouco discutido -, consiste no silenciamento do aluno diante das veredas interpretativas suscitadas pelo texto literário. Com o intuito de contribuir para a superação desse problema, o presente artigo tem o objetivo de discutir a colaboração como um movimento "ético-poético" de grande relevância para (re)pensar a organizaça das aulas de literatura. Tal discusso propostos por Magaliñes $(2016,20$ propostos por Magalhas (2016, 2014, 2012), entre outros autores. Espera-se, a partir das reflexões aqui expostas, contribuir para ressignificar o ensino de literatura, favorecendo a criação de relações colaborativas em sala de aula e conduzindo à transformação dos sujeitos ali envolvidos.

PALAVRAS-CHAVE: Colaboração. Ensino de Literatura. ZPD.
* rodolfomeissner@yahoo.com.br

Mestre em Linguística Aplicada pela Universidade de Taubaté. Doutorando em Linguística Aplicada e Estudos da Linguagem pela
Pontifícia Universidade Católica de São Paulo (PUC-SP).

ABSTRACT: Researchers like Cereja (2005), Cosson (2006.2014), Paulino Cosson(2009) and Zilmerman and Rösing (2009), among others, have indicated, in their studies, a crisis in the literature teaching. In this sense, one of the main problems arising from this crisis - still little discussed- consists in the student`s silence on the interpretive paths raised by the literary text. In order to contribute to overcome this issue, this article aims to discuss collaboration as an "ethical and poetic" movement, indispensable to think the literature classes's organization. This proposition anchors itself on the theoretical studies about collaboration as propose It is expected that based on it is expected that based on the reflections exposed over this article, a contribution be made to reframe the literature teaching, helping to create collaborative relationships in the classroom and leading to the transformation of individuals therein involved.

KEYWORDS: Collaboration. Literature teaching. ZPD. 
Transformar o mundo, disse Marx; mudar a vida, disse Rimbaud: estas duas palavras de ordem são, para nós, uma só.

André Breton (Manifestos do Surrealismo)

\section{INTRODUÇÃO}

A educação formal brasileira surgiu como uma reprodução do modelo educacional europeu vigente entre os séculos XIV e XVI. Nesse processo embrionário, os jesuítas portugueses foram, de forma ampla, os primeiros educadores do Brasil. Ferrarezi Jr. (2014) comenta que, nesse período, a prática pedagógica corriqueira era a catequese, que tinha por objetivo "curar" o paganismo entre índios e entre escravos africanos, impondo a eles a cultura cristã. Para isso, os castigos físicos e a exposição autoritária eram instrumentos mortificadores da cultura desses povos e levavam a um silenciamento das vontades, sentimentos e dizeres dos povos catequizados. De acordo com o autor, "a mortificação do corpo, a penitência, a dor como forma de cura da alma corrompida permaneciam como concepção básica de educação. Isso veio de longe, mas chegou bem aí pertinho, aos nossos pés na história".

Mais recentemente, na vigência do golpe militar vivido pelo Brasil entre 1964 e 1985, com base no que então, nas escolas, intitulava-se "educação moral e cívica", o Brasil esteve interessado em formar "o bom aluno disciplinado". Esse estudante representava um indivíduo propenso a seguir a hierarquia e era valorizado pelo seu comportamento calado e obediente. Toda forma de contestação - vista, na verdade, como "subversão" - era condenável. Ferrarezi Jr. argumenta que "por razões muito menos nobres do que aquelas que a catequese defendia, mas igualmente mortificadoras, os grupos escolares públicos Brasil afora [...] privilegiavam aqueles alunos que conseguiam se manter calados e conformados". ${ }^{2}$

No âmbito maior dessa educação autoritária e silenciadora, é possível pensar que as aulas de literatura, objetivo central da discussão deste artigo, não estão, infelizmente, distantes desses apontamentos. Ao contrário. Como explicam Souza (1999) e Magnani (2001), em seus respectivos trabalhos, a literatura representou, sobretudo no período colonial brasileiro, uma forma de afirmação política atrelada aos interesses europeus e aos padres jesuítas, tida como a manifestação de uma cultura superior e, portanto, digna de contemplação. Essa visão sobre o fenômeno literário se estendeu até os séculos XVIII e XIX. Nessa época, a literatura passa a ser vinculada, já como disciplina escolar, aos projetos de construção de uma identidade nacional, pouca ou nenhuma atenção sendo dada aos interesses discentes.

Assim, a literatura foi se constituindo, na educação formal, como disciplina completamente alheia à realidade dos estudantes. Sendo o texto literário subversivo e polissêmico por excelência, é contraditório notar que tal disciplina tenha se
2. FERRAREZI JR. Pedagogia do silenciamento: a escola brasileira e o ensino de língua materna, p. 23
EM TESE BELO HORIZONTE $\quad$ v. 22 N. 3 SET.-DEz. 2016 ROLANDO. A colaboração como movimento ético-poético a caminho do [...] P. 203-218 
3. TIBURI. Filosofia prática: ética vida cotidiana, vida virtual, p.18 afastado da vivência dos estudantes e negligenciado, muitas vezes, a voz interpretativa do aluno no processo de leitura desse tipo de texto. O professor de literatura, alicerçado pela crítica literária e pela interpretação canônica já cristalizada sobre as obras clássicas, parece, muitas vezes, não considerar os estudantes como sujeitos capazes de adentrarem no jogo interpretativo suscitado pelo fenômeno literário.

Pode-se perceber, dessa maneira, que, mesmo hoje, distante daqueles tempos de catequese jesuítica ou construção burguesa de uma identidade nacional, o ensino de literatura vivencia uma profunda crise, como denunciam os trabalhos de Cereja (2005), Cosson (2006, 2014), Paulino e Cosson (2009) e Zilmerman e Rösing (2009), entre outros. Uma crise que passa, fundamentalmente, pelo silêncio do estudante e pela profunda assimetria de papeis entre professor e aluno nas aulas de literatura.

Nesse sentido, o objetivo deste artigo é discutir a colaboração como um movimento "ético-poético" de grande relevância para (re)pensar a organização das aulas de literatura. O termo "ético-poético" - esmiuçado mais à frente - foi emprestado de Tiburi (2016) e representa, nas palavras da autora, "o pensamento criativo da ação". ${ }^{3}$ Isto é, tal termo indica, na visão da autora, a possibilidade de um agir transformativo atrelado ao pensamento crítico e reflexivo sobre a realidade. Dessa forma, objetiva-se, por meio das proposições deste artigo, destacar as relações colaborativas como forma de superar o autoritarismo vigente no ensino de literatura favorecendo a voz discente na interpretação do texto literário e levando todos os sujeitos da aula a uma transformação de seus papeis. Mais especificamente, pretende-se, com essa proposição, valorizar os sentidos imprevistos despertados pelo texto literário em uma aula de literatura, opondo-se às interpretações cristalizadas e "inquestionáveis" que parecem sustentar a organização das aulas dessa disciplina.

Para tanto, este artigo se apoia teoricamente nas discussões sobre colaboração realizadas por Magalhães $(2009,20112012$ 2014, 2016), Ninin (2013), Magalhães e Oliveira (2011, 2016), John-Steiner (2000) e Freire ([1967] 2015). As discussões Vygotskyanas ([1934] 2007) sobre ZPD, além de autores que têm expandido esse conceito, tais como Newman e Holzman (2002), Holzman (2010), Magalhães (2009) e Engeström (2008), também darão sustentação à discussão aqui proposta.

Sendo assim, para fins de organização, este texto obedecerá a seguinte divisão: 1 . Discute a crise no ensino de literatura e destaca o silenciamento da voz do aluno como consequência dessa crise; 2 . Propõe e discute a colaboração como movimento "ético-poético" capaz de superar alguns obstáculos no ensino de literatura; 3. Aborda a ZPD como possibilidade de criação do "novo" e resgate da voz discente no processo de leitura do texto literário. 
4. MAGNANI. Leitura, Literatura e Escola: sobre a formação do gosto, p. 17.

\section{A CRISE NO ENSINO DE LITERATURA E O SILENCIA- MENTO DO ALUNO: UMA TRISTE REALIDADE NAS \\ ESCOLAS BRASILEIRAS}

Para se compreender melhor a referida crise no ensino de literatura, o histórico dessa disciplina no ensino brasileiro será brevemente comentado. Para isso, os apontamentos de Souza (1999) oferecem importantes contribuições. O autor explica que, no período colonial, naquilo que concerne à educação formal, houve uma predominância de estudos que privilegiavam o latim e a sua literatura, a gramática portuguesa e a retórica.

Magnani (2001), na mesma direção, acrescenta que, sob a ação dos padres jesuítas, houve, naquele momento, uma tendência de perceber a literatura como uma forma de afirmação política de um país ainda em formação. Nesse sentido, o fenômeno literário representava a manifestação de uma cultura "bela" e "perfeita", digna de contemplação, afastando-se, portanto, de qualquer possibilidade de interrogação e questionamento por parte do estudante. No dizer de autora, "a educação jesuítica com sua tradição literária e retórica foi, nesse sentido, a arma mais poderosa de colonização do nosso país". ${ }^{4}$ Isso evidencia o que estava por trás dos primórdios do ensino de literatura no Brasil: colonizar os indivíduos, impondo a eles os valores cristãos e a cultura europeia, silenciando, portanto, qualquer possibilidade de formação ética e/ou estética.
Ademais, os padres jesuítas ignoraram o substrato humano que estava se formando naquele momento na sociedade brasileira, superpondo uma cultura elitista e refinada, inspirada nos clássicos latinos e mais identificada à Europa. Como lembram Zanini e Santos (2012), esse distanciamento da realidade, no que tange à escolarização da literatura, permaneceu, de modo abrangente, na educação brasileira.

Essa visão de literatura, típica dos primórdios do Brasil, se conservou, de certo modo, até os séculos XVIII e XIX, como explica Magnani. Nesse período, de acordo com Souza (1999), os estudos literários se consolidam no país, período em que se inicia o que mais tarde veio a ser chamado de "crítica literária". Sobre esse ponto, o autor afirma que o estabelecimento da literatura como disciplina esteve estreitamente atrelado aos projetos nacionalistas de construção da identidade nacional, característicos daquele momento histórico. No final do século XIX, nas palavras de Magnani:

A educação se torna uma bandeira de luta, no período pós-republicano, e surge como caminho natural para a difusão de ideias nacionalistas, fazendo-se acompanhar da criação de uma literatura especificamente escolar, que traz os ecos europeus do desenvolvimento do gênero e se apresenta como veículo dos valores que à escola cumpre difundir $[. . .]^{5}$
5. MAGNANI. Leitura, Literatura e Escola: sobre a formação do gosto, p. 21.
EM TESE BELO HORIZONTE $\quad$ v. $22 \quad$ N. 3 SET.-DEz. 2016 ROLANDO. A colaboração como movimento ético-poético a caminho do [...] P. 203-218 
Como se percebe, seja como escopo representativo das belas letras a que se devia admirar sem contestações, seja como instrumento ideológico representativo de certos valores que à escola cumpria difundir, a literatura foi se constituindo, na educação formal, como disciplina completamente distante da realidade dos estudantes e de seus interesses. Dessa maneira, pode-se perceber que, mesmo hoje, distante daqueles tempos de catequese jesuítica ou formação burguesa, o ensino de literatura vivencia uma profunda crise, como denunciam inúmeros trabalhos, dentre eles os Cereja (2005) Cosson (2006, 2014), Paulino e Cosson (2009) e Zilmerman e Rösing (2009), Zinani e Santos (2012), por exemplo.

Pensando sobre os desafios enfrentados pela disciplina de literatura no Ensino Médio nos dias atuais, Zinani e Santos (2012) oferecem uma importante constatação. Segundo as autoras, a literatura encontra-se sufocada. Isso se deve, em grande medida, às exigências do vestibular - que determina o conteúdo e a abordagem da disciplina. Em consequência disso, cria-se um obstáculo ao professor, uma vez que cabe ao docente despertar o gosto e o interesse discentes em meio a essas exigências.

Sobre essa dificuldade em despertar o interesse discente pela literatura, Paulino e Cosson (2009) apontam alguns elementos que dificultam ou mesmo impedem a formação de leitores de literatura na tradição escolar. Segundo os autores, muitas vezes, a escola enfatiza apenas aquilo que é conhecido e mensurável. Isso se comprova, por exemplo, na figura do aluno cuja competência mais reconhecida é repetir o que o professor disse ou o que o livro didático apresenta. E, naquilo que concerne ao papel do professor de literatura, pode-se dizer que, apoiado na crítica literária e em interpretações já cristalizadas sobre determinadas obras, estéticas e autores, o docente representa, muitas vezes, o papel de um "sábio" a quem cumpre desvendar os segredos do texto; ao aluno, relegando-se o papel de "ouvinte" a quem compete ouvir e repetir o que o professor "ensinou". Nesse modelo bancário (Freire, [1967] 2015), não há espaço para o inusitado e a subversão, marcas essenciais do texto literário.

Sobre esse ponto, Martins (2006) denuncia que a escola, no que se refere ao estudo do texto literário, parece supervalorizar a intenção do autor, tornando a literatura, para o aluno, um objeto impenetrável. A respeito do papel do estudante em uma aula de literatura, a autora afirma que "o aluno-leitor não se conscientiza de sua participação como co-enunciador do texto, pois seu papel na recepção textual não é tão privilegiado”. ${ }^{6}$ Em direção contrária ao que se faz, normalmente, nas escolas brasileiras, as palavras de Rouxel lembram o papel de aluno que se devia esperar, de fato, em uma aula de literatura:

É a formação de um sujeito leitor livre, responsável e crítico - capaz de construir o sentido de modo autônomo e de argumentar sua recepção - que é prevista aqui. É também,
6. MARTINS. A literatura no Ensino Médio: quais os desafios do professor?, p. 93

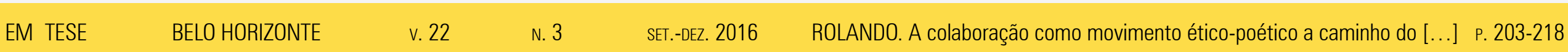

Teoria da Literatura e Ensino de Literatura 
7. ROUXEL. Aspectos metodológicos do ensino de literatura, p. 20

8. PAULINO; COSSON. Letramento literário: para viver a literatura dentro e fora da escola, p. 72. obviamente, a formação de uma personalidade sensível e inteligente, aberta aos outros e ao mundo que esse ensino de literatura vislumbra.?

No entanto, como se discute aqui, não é isso o que ocorre. Nesse sentido, ainda sobre os problemas vividos pelo ensino de literatura, Paulino e Cosson (2009) apontam também as contradições da cultura letrada em âmbito escolar. Para eles, a escola é impelida a buscar um letramento funcional e básico na tentativa de agradar a uma sociedade já estruturada, com funções predefinidas para os sujeitos. Assim, os autores comentam que, quando surgem textos e práticas que possibilitam uma interação questionadora, poética e aberta - marcas do fenômeno literário -, a tendência de parte dos educadores é negar os sentidos imprevistos na esfera escolar, silenciando a voz discente em busca pelo consenso e pela homogeneização.

Os autoresexpõem ainda que a disciplina de literatura se fecha em biografismo e historicismo, o que representa um importante problema.

Cai-se assim num elitismo cultural de fachada, de almanaque em que o conhecimento é aprendido sem integrar-se às vidas dos alunos enquanto sujeitos. A soma de conhecimentos sobre literatura é o que interessa, não a experiência literária. ${ }^{8}$

Corroborando essa crítica, Cosson (2014) afirma que o ensino de literatura tem se limitado à história da literatura brasi- leira, quase apenas como uma cronologia literária. De acordo com o pesquisador, a partir de uma perspectiva transmissiva e tradicional, ocorre, nas escolas, uma sucessão insossa e alienante entre identificação de características das escolas literárias, dados biográficos do autor, gêneros literários, entre outras atividades mecânicas. O texto literário em si, quando se faz presente, é estudado a partir de "fragmentos e serve prioritariamente para comprovar as características dos períodos literários antes nomeados".

Sob a mesma ótica, Martins (2006) acrescenta que, muitas vezes, a postura tradicional no ensino de literatura negligencia os aspectos sociais, históricos, políticos e ideológicos ligados ao texto literário, o que implica aulas desinteressantes e distantes da realidade do aluno. Se isso não for alterado, segundo a autora, as aulas continuarão insossas. Isso pode ser explicado, em parte, pelos "exercícios fragmentados e repetitivos de boa parte dos livros didáticos, à postura tradicional diante do texto literário, à avaliação da leitura literária como forma de punição e não de prazer" ${ }^{10}$

Dessa forma, com base no exposto, torna-se evidente a necessidade de se (re)pensar o ensino de literatura como fenômeno capaz de atrair o interesse do estudante, propiciando o desenvolvimento do seu potencial crítico e reflexivo e valorizando a sua voz na recepção do texto literário. No entanto, nessa busca por novos caminhos teórico-metodológicos
9. cosson Círculos de leitura letramento literário, p. 21.

\section{MARTINS. A literatura no Ensino Médio: quais os desafios do}

professor?, p. 100
EM TESE BELO HORIZONTE $\quad$ V. $22 \quad$ N. $3 \quad$ SET.-DEz. 2016 ROLANDO. A colaboração como movimento ético-poético a caminho do [...] P. 203-218 
11. MAGALHÃES; OLIVEIRA. Argumentação na construção de contextos colaborativos em pesquisas com formação de educadores, p. 211. para o ensino de literatura, emerge uma indagação crucial: a colaboração poderia auxiliar o professor de literatura no enfrentamento dos obstáculos aqui apontados?

\section{A COLABORAÇÃO COMO MOVIMENTO “ÉTICO- POÉTICO": A TRANSFORMAÇÃO CRÍTICO-CRIATIVA DOS SUJEITOS NA AULA DE LITERATURA}

A colaboração pode ser compreendida, de acordo com Magalhães $(2009,2014)$, como os diversos modos em que a relação com os outros, em diversos contextos, favorecem aprendizagem e desenvolvimento à medida que os sujeitos atuem como apoio uns dos outros. A autora explica ainda que o processo colaborativo possibilita que os participantes compreendam criticamente os seus próprios processos mentais, expliquem e deixem claros os seus pontos de vista e as suas condutas e, desse modo, ocorra a expansão do objeto posto em discussão, criando novas formas de pensar de agir. Sobre a colaboração, nas palavras de Magalhães e Oliveira:

Esse processo implica questionamentos que propiciem que contradições entre as diversas compreensões do objeto em discussão sejam pontuadas, sentidos sejam retomados, revistos e transformados, e novos significados sejam produzidos no processo de compartilhamento. ${ }^{11}$
Na mesma direção, Ninin (2013), define a colaboração como um processo interacional de criação compartilhada mediado pela linguagem, que tem a prática social entre indivíduos como origem. Os participantes dessa interação, histórico e culturalmente situados, buscam reconstruir e reorganizar os saberes do contexto do qual participam.

Magalhães e Oliveira (2016) corroboram essa definição e explicam que a colaboração potencializa um movimento de mutualidade e reciprocidade na compreensão de si, do outro, do contexto em que ocorre a interação e da sociedade mais ampla. Dessa maneira, tal movimento representa uma possibilidade de "transformação de contextos, como resultado de um processo de conscientização sobre a própria prática e a do outro, geralmente, aliada ao aprofundamento prático, teórico e crítico da realidade". ${ }^{12}$

Em outras palavras, a essência do movimento colaborativo envolve um olhar crítico e consciente do sujeito de dado contexto sobre si e sobre o outro com quem interage. A alteridade, portanto, é um traço constitutivo do processo de colaboração verdadeira. "O outro" se apresenta como uma singularidade concreta a se colocar diante do "eu" no movimento colaborativo, o que está, por conseguinte, na base de qualquer discussão que se proponha "ética".

Ao encontro desse apontamento, Tiburi assevera que "se o outro é o foco do pensamento ético, está dado que o
12. MAGALHÃES; OLIVEIRA. Argumentação na construção de contextos colaborativos em pesquisas com formação de educadores, p. 211.

EM TESE BELO HORIZONTE $\quad$ v. $22 \quad$ N. $3 \quad$ SET.-DEz. 2016 ROLANDO. A colaboração como movimento ético-poético a caminho do [...] P. 203-218


13. TIBURI. Filosofia prática: ética, vida cotidiana, vida virtual, p. 26.

14. TIBURI. Filosofia prática: ética, vida cotidiana, vida virtual, p. 27.

15. RICOUER apud LA TAILLE. $A$ escola e os valores: a ação do professor, p. 22

16. BARROS FILHO; CORTELLA Ética e vergonha na cara!, p. 40 pensamento ético só pode ser o pensamento da relação". ${ }^{13}$ A autora ainda acrescenta que não há ética que se sustente sem a constatação iniludível da alteridade, pois "o caminho ao outro é a questão de toda ética”. ${ }^{14}$

Em função do exposto e da complexidade do tema "ética" no âmbito maior das Ciências Humanas, faz-se mister apresentar uma definição mais concreta sobre o que este artigo entende pelo termo. Entre inúmeras possibilidades, a definição atribuída ao pensador Paul Ricoeur (1990, apu LA TAILLE, 2013, p.22), clarifica a visão sobre ética aqui discutida. De acordo com o filósofo, a perspectiva ética é a "perspectiva de uma vida boa, com outrem e para outrem no seio de instituições justas". ${ }^{15}$

Para ampliar o que aqui se pretende propor, Barros-Filho (2014) oferece uma explicação pertinente. Apoiando-se no filósofo Rosseau, o autor chama a atenção para a capacidade humana de transcender a natureza e aponta, nessa transcendência, o surgimento da ética. Para ele, ética seria a capacidade humana de realizar escolhas e criar caminhos a serem seguidos, uma vez que o homem é capaz de superar os seus instintos e ir além de suas inclinações puramente biológicas. No dizer do autor, a ética é "muito mais que uma inclinação do corpo, é uma decisão racional, elaborada e criativa sobre para onde queremos ir". ${ }^{16}$
E, na superação de seus limites biológicos, o homem encontra apoio em seus semelhantes, pautando e fortalecendo as suas decisões. Nesse sentido, John-Steiner (2000, p.188) destaca que por meio do trabalho colaborativo "podemos transcender as limitações da biologia, do tempo, do hábito" e, para além do isolamento e do individualismo, o homem pode se constituir como "um outro eu". ${ }^{17}$ Revelando visão semelhante à da autora, Freire ([1967] 2015), aponta que o "eu" e o "tu" passam a ser, em relações eticamente dialógicas e transformativas, dois "tu" que se fazem dois "eu". Segundo o autor, não há, em um processo efetivamente dialógico, conquistador e dominado, mas "sujeitos que se encontram para a pronúncia do mundo, para a sua transformação” (FREIRE, 2015, p.227). ${ }^{18}$

Partindo dessa visão de ética como fenômeno primordialmente dialógico, é importante pontuar - ainda que brevemente - a visão bakhtiniana sobre a questão. Bakhtin/ Volochínov ([1929] 2014), questionando a visão de um sujeito isolado e monológico, advogam uma visão ética centrada na alteridade. De acordo com Fanini (2015), a dimensão ética do outro representa o alicerce do pensamento bakhtiniano, que não acredita em uma verdade monológica do sujeito isolado nem em uma verdade objetiva advinda de um sistema universal de normas. Para o pensador russo, é justamente na interação social, cultural, histórica e verbal que os
17. JOHN-STEINER. Creative Collaboration, p. 188.

18. FREIRE. Pedagogia do oprimido, p. 227.
EM TESE BELO HORIZONTE $\quad$ v. $22 \quad$ N. 3 SET.-DEz. 2016 ROLANDO. A colaboração como movimento ético-poético a caminho do [...] P. 203-218

Teoria da Literatura e Ensino de Literatura 
19. MAGALHÃES; OLIVEIRA. Argumentação na construção de contextos colaborativos em pesquisas com formação de educadores, p. 212. sujeitos se constituem em uma perspectiva ética dialógica, claramente calcada na dimensão da alteridade.

Assim sendo, ao realizar escolhas conscientes diante das infindáveis possibilidades oferecidas pela vida propriamente vivida, assentando-se em valores democráticos de justiça e igualdade e tendo a relação com o outro como centro de tais escolhas e vivências, estar-se-á diante da perspectiva ética. Por conseguinte, o movimento colaborativo é - inescapavelmente - ético.

Conforme evidenciam Magalhães e Oliveira, a Colaboração pode ser entendida como uma categoria filosófica, configurando-se como um movimento coletivo para gerar, nas atividades, uma relação "voltada à necessária superação do cotidiano, das transformações do real, em um movimento conjunto que não se limita às ações repetidas, reiteradas e reificadas" ${ }^{19}$ Nesse ponto, este artigo propõe um breve acréscimo: a Colaboração pode ser compreendida como uma categoria filosófica e necessariamente "ética".

Relacionando o que foi exposto até aqui às aulas de literatura, é fácil perceber o papel fundamental que as relações colaborativas podem exercer para a superação das leituras habitualmente mecanizadas do texto literário e do autoritarismo interpretativo do professor, observáveis, normalmente, nas escolas brasileiras. Criticando a perspectiva individualista

\begin{abstract}
BELO HORIZONTE
\end{abstract}
N. 3

SET.-DEZ. 2016 que parece perpassar, historicamente, a relação homem-leitura, Fanini argue que "na sala de aula, sobretudo, teremos a leitura do professor erigida à máxima universal, sendo esperada que se replique e multiplique entre os alunos". ${ }^{20}$

Articulando essa assertiva às aulas de literatura, é lícito afirmar que, muitas vezes, as situações de ensino-aprendizagem dessa disciplina partem de interpretações pré-concebidas e já cristalizadas sobre os textos literários e solicitam dos estudantes compreensões pré-determinadas sobre os objetos supostamente postos em discussão. Ou seja, em geral, as aulas de literatura são organizadas a partir da perspectiva exclusiva do professor, oferecendo pouco espaço de valorização dos anseios discentes. De encontro a esse formato, a colaboração pode favorecer que as aulas de literatura organizem-se com base em uma perspectiva mais dialética e dialógica, valorizando, dessa maneira, as necessidade de todos os sujeitos constitutivos da aula.

Sem a ilusão de superação definitiva das hierarquias ou das relações de poder existentes nas salas de aula, assumir uma postura colaborativamente ética e responsável em uma aula de literatura implica - tomando como base as palavras de Mateus sobre o processo educativo, "comprometer-se com a criação de espaços seguros que promovam práticas discursivas dialógicas e que potencializem as oportunidades para que todos possam agir e ocupar posicionamentos múltiplos”. ${ }^{21}$

ROLANDO. A colaboração como movimento ético-poético a caminho do [...] P. 203-218
20. FANINI. Embate dialógico entre leitura e escrita: manifestação de uma ética da ação discursiva a partir do Círculo bakhtiniano, p. 23.

21. MATEUS. Por uma pedagogia da argumentação, p. 41.

\section{Teoria da literatura e Ensino de literatura}


22. TIBURI. Filosofia prática: ética, vida cotidiana, vida virtual, p. 20.
Não obstante, mais do que um movimento ético, a colaboração pode ser compreendida como um "movimento poético" ou ainda "ético-poético" em termo aqui emprestado da filósofa Tiburi (2016). Utilizando a palavra "poético" em sentido mais extenso, a autora se refere a uma "ético-poética" como um pensamento criativo que volta a sua ação para a vida. Com o intuito de superar os ditames opressores do neoliberalismo e a reificação do homem que se dá pelo consumo exacerbado dos tempos hodiernos, a autora propõe uma ético-poética como uma forma transformadora e criativa de se fazer contato com as coisas no mundo e com os outros, engendrando um pensamento íntimo da ação e contribuindo para a construção de relações dialógicas. Segundo ela:

O controle das práticas dialógicas se dá pela sedução ao imediato, ao mais-do-mesmo, pela criação do jargão dos especialistas que impera sobre o senso comum que o repete como um ventríloquo. [...] Portanto, libertar a linguagem ordinária, libertar o dizer dos discursos prontos, dar-lhe o espírito do diálogo e da expressão, devolvendo assim a experiência ao corpo e à linguagem de cada um em seu encontro com o mundo. Tudo isso é o que espera esta filosofia prática enquanto prática ético-poética. ${ }^{22}$

Nesse sentido, é possível ver, no movimento colaborativo, os traços de uma ética que se pretende também poética, uma vez que a alteridade, o diálogo, o olhar crítico e consciente sobre si, o mundo e o outro e a transformação das relações e da realidade circundante constituem os alicerces desse movimento. E, se esse processo for pensado como possibilidade teórico-metodológica para o ensino de literatura, poder-se-ia estar mais próximo de resgatar o interesse discente pelo fenômeno literário, desprezado, nos últimos tempos, pela supremacia do conhecimento técnico-científico instrumentalizado e pelos poderes de sedução do marketing interessados em formar "consumidores" destituídos de sua cidadania.

Esse despertar do interesse do estudante poderia ser conquistado à medida que a sua voz fosse verdadeiramente ouvida por meio de um movimento colaborativo. A partir de um diálogo autêntico e crítico entre professor/aluno/texto/ contexto, seria possível estabelecer relações menos assimétricas entre os sujeitos aí envolvidos, acolhendo os sentidos discentes suscitados pelo processo de leitura dos textos literários. A escuta e o acolhimento do aluno representaria, dessa forma, um passo essencial para superar, ao menos em partes, a crise vivida por tal disciplina.

No contexto de aulas de literatura, o agir colaborativo pode ser propulsor de re-descobertas de si e do outro, em conexão criadora e inventiva com a vida. Possibilidade real de poetizar a aprendizagem em um processo em que as vozes de todos os sujeitos na aula são re-encontradas - porque efetivamente ouvidas. Em função disso, talvez fosse possível compreender
EM TESE
BELO HORIZONTE
N. 3
SET.-DEz. 2016
ROLANDO. A colaboração como movimento ético-poético a caminho do [...] . 203-218

Teoria da Literatura e Ensino de Literatura 
23. MAGALHÃES. Escolhas teóricometodológicas em pesquisas com formação de professores: as relações colaborativos-crítica na constituição de educadores, p. 25

24. NININ. Da pergunta como ato monológico avaliativo à pergunta como espaço para expansão dialógica: uma investigação à luz da linguística aplicada sobre modos de perguntar, p. 53. verdadeiramente a leitura como um ato co-criativo entre professor/aluno e entre os próprios alunos diante do texto literário. Sendo a leitura como criação um processo insubstituível, descobrir novas relações e possibilidades interpretativas diante da literatura - a partir de um movimento colaborativo ético-poético - desvela um horizonte profícuo em transformações dos homens e da própria vida. Como explica Magalhães:

colaboração é primeiramente um construto filosófico central, que organiza experiências coletivas pelas quais os seres humanos se constituem e se transformam constantemente e, do mesmo modo, criam e transformam seus contextos de ação.

Desse modo, como aponta John-Steiner (2000), ao contrário do que apregoa as teorias educativas tradicionais, cujo foco está no indivíduo, tomar a parceria colaborativa como foco enfatiza o movimento dialético entre os processos individuais e sociais. Essa questão foi discutida por Vygotsky ([1934] 2007) em seus estudos sobre a zona de desenvolvimento proximal, o que passa a ser mais detalhadamente discutido na próxima seção deste artigo.

ZPD: ESPAÇO DE COLABORAÇÃO, CONTRADIÇÃO E CONSTRUÇÃO DO NOVO NAS AULAS DE LITERATURA

Para Vygotsky ([1934] 2007), a Zona de Desenvolvimento Proximal - ZPD (do inglês, zone of proximal development)
- representa a distância entra aquilo que a criança já consegue realizar sozinha - desenvolvimento real - e aquilo que ela consegue fazer com a ajuda de um adulto ou alguém mais experiente que ela - desenvolvimento potencial. Ou seja, para o teórico, é neste espaço entre o "real" e o "potencial", tendo em vista a relevância da interação e da inserção dos indivíduos em práticas sociais, que o desenvolvimento e as transformações acontecem.

No entanto, o conceito de ZPD vem passando por algumas expansões desde a sua formulação por Vygotsky. Como comenta Ninin (2013), há muitas discussões sobre esse conceito e tais discussões têm sido realizadas por diferentes autores, nos mais diversos contextos educacionais e sob a tutela dos mais diversos objetivos. Dessa maneira, apesar de possíveis divergências teóricas, a autora pontua que prevalece o fato de que "é nesse espaço imaterial, não mensurável, onde circulam as dissonâncias, conflitos e contradições com as quais convive o ser humano em função de sua sociohistórica, que toda atividade de aprendizagem ocorre". ${ }^{24}$

Magalhães (2012), na mesma direção, destaca que o conceito de ZPD tem sido expandido nos últimos anos, passando a ser compreendido como um movimento de colaboração e contradição, mediado pela linguagem, constituindo relações de compreensão e ressignificação de sentidos e de produção compartilhada de significados. Apoiando-se em Newman e
EM TESE
BELO HORIZONTE
N. 3
SET.-DEz. 2016
ROLANDO. A colaboração como movimento ético-poético a caminho do [...] . 203-218

Teoria da literatura e Ensino de literatura 
Holzman ([1993] 2002), a pesquisadora explica que a ZPD não representa um "lugar" ou um "instrumento", mas uma abstração, um "espaço de vida”. Isso significa, segundo a autora, que as ações dos sujeitos, histórico e culturalmente situadas, são inevitavelmente motivadas pelas ações dos outros e produzidas a partir dessas ações, o que evidencia o caráter essencialmente dialógico e colaborativo desse movimento.

Sobre essa questão, Magalhães e Fidalgo (2007) chamam a atenção para o papel central da colaboração na ZPD, uma vez que os sujeitos nela envolvidos participam de uma negociação coletiva de novos significados e, dessa maneira, procuram construir relações de confiança. Nesse sentido, se o texto literário for tomado colaborativamente como objeto de investigação coletiva em sala de aula, poder-se-ia gerar, a partir de ZPD, novas interpretações do texto, valorizando a descoberta e o inusitado: características ontológicas do fenômeno literário.

Em relação a esse ponto, faz-se necessária uma ressalva: não se pode pensar a ZPD como uma relação de colaboração confortável e negociação harmoniosa de significados, negligenciando, nesse processo, as contradições como possibilidades potencializadoras de criação do novo.

Engeström (2008) oferece sustentação a essa ressalva destaca a complexidade de processos envolvidos na criação de ZPD, já que tal relação está imbricada com questões de poder, tensões, contradições, desafios e conflitos. São essas contradições, na visão do autor, que podem contribuir para a (re) elaboração de sentidos e superação de significados cristalizados em um determinado contexto, contribuindo, desse modo, para a gestação do novo. Assim, as contradições podem aparecer em função da historicidade dos sujeitos necessariamente presente nos sentidos despertados em cada indivíduo pelo texto literário. Cabe ao professor de literatura não só não impedir que tais contradições se evidenciem, como valorizá-las em sua aula a fim de favorecer o processo co-criativo de leitura do texto literário.

Holzman (2010), ao encontro dessa concepção, afirma que a criação de ZPD é um construto fundamental para a instauração do novo e para o entendimento da criatividade, vista como atividade necessariamente social e coletiva, superando a perspectiva do senso comum que vê o ato criativo como fruto da individualidade do sujeito. Magalhães compartilha dessa visão e acrescenta que a ZPD pode ser compreendida como "uma zona de ação criativa, uma atividade transformadora "prático-crítica”, em que colaboração e criticidade são imprescindíveis à possibilidade de criação de novas trilhas (desenvolvimento)".

Comentando a relação entre a ZPD e a construção de novos saberes, Magalhães e Oliveira (2011, p. 107) entendem a ZPD como um processo inter-intra-extra psicológico, "característico da produção de sentidos, na e pela linguagem, um
25. MAGALHÃES. O método para Vygotsky: a zona proximal de de colaborã̃o criticidade criativas, p. 61. 
26. MAGALHÃES; OLIVEIRA. Vygotsky e Bakhtin/Volochinov: dialogia e alteridade, p. 107.

27. NEWMAN; HOLZMAN. LeV Vygotksy: cientista revolucionário p. 110. movimento de organização de linguagem nas relações interpessoais que criam contextos para aprendizagem e desenvolvimento". ${ }^{26}$ Ao encontro dessa ideia, Newman e Holzman afirmam que "a ZPD permite uma reorganização dos cenários ambientais para criar novo significado e uma aprendizagem que conduz o desenvolvimento". ${ }^{27}$ Os autores apontam ainda que a ZPD funciona como "atividade revolucionária", evidenciando, assim, o seu potencial transformativo.

É justamente essa possibilidade transformativa propiciada pela/na construção de ZPD que interessa - em especial- a este artigo. Isso porque a criação dessa relação no âmbito da escola poderia favorecer não apenas a aprendizagem de conteúdos específicos, mas também a compreensão de novas formas de agir, criando espaços, em sala de aula, de questionamento e reflexão crítica, na tentativa de estabelecer relações entre o cotidiano dos alunos, os conceitos escolares relacionados ao ensino de literatura e a sociedade mais ampla. Mais do que isso: a partir da criação de ZPD poder-se-ia estar mais próximo da superação do silenciamento do aluno vigente nas aulas de literatura, o que, na visão deste trabalho, tem sido um dos principais entraves no ensino de tal disciplina.

\section{CONSIDERAÇÕES FINAIS}

Tendo em vista o objetivo deste artigo em propor e discutir a colaboração como um movimento "ético-poético" indispensável à organização das aulas de literatura, cabe destacar que as proposições aqui discutidas pretendem contribuir para ressignificar o ensino de literatura, colaborando, dessa forma, para a superação do silenciamento discente naquilo que concerne à interpretação e à discussão do texto literário em sala de aula.

Mais do que isso: a organização colaborativa das aulas de literatura favorece a possibilidade de transformação do homem e da sociedade à medida que evidencia a relação com o outro como pressuposto indispensável no encontro autêntico com o fenômeno literário. Afinal, como ensinou Vygotsky ([1934] 2007), a transformação e o desenvolvimento do homem ocorrem, invariavelmente, a partir de sua inserção em práticas socioculturais, isto é, o contato com o outro representa a mola propulsora da mudança e, portanto, a base de toda ética, conforme exposto ao longo deste texto.

Portanto, mais que resgatar a voz do estudante em uma aula de literatura, o movimento ético e poético propiciado pela colaboração pode engendrar aquilo que toda a educação almeja (ou deveria): a projeção de um futuro mais justo e igualitário no seio de relações humanas abertas à diversidade que constitui a convivência. Em meio a essas relações, a divergência, o diálogo, as diferentes visões de mundo e as inúmeras formas de expressão seriam escopo de um ensino apto a ultrapassar a pasteurização vigente em boa parte das escolas brasileiras.
EM TESE
BELO HORIZONTE
v. 22
N. 3
SET.-DEZ. 2016
ROLANDO. A colaboração como movimento ético-poético a caminho do [...] . 203-218

Teoria da literatura e Ensino de literatura 
Não obstante, no que se refere às aulas de literatura propriamente ditas, pretende-se também, por meio das reflexões aqui expostas, auxiliar o professor a despertar o gosto do aluno pela literatura em um mundo em que o fenômeno literário tem sido cada vez mais sufocado. Ao valorizar a voz do estudante na aula de literatura, o docente pode fomentar - verdadeiramente - o questionamento crítico do mundo, a capacidade de escuta e compreensão da palavra do outro, o pensamento reflexivo e a autonomia em sala de aula.

Para além da mutilação imposta pelos vestibulares e das homogeneizações técnico-científicas sedimentadas pelo "mercado de trabalho" - características das expectativas outorgadas aos adolescentes no Ensino Médio -, o fazer colaborativo aponta para um caminho mais humanizado, sensível e democrático na organização do ensino literário.

Esse poderia ser um primeiro passo para o enfrentamento do silenciamento inaceitável observado nas aulas de literatura de boa parte das escolas brasileiras. Superar esse silêncio é retirar a educação de sua inércia petrificadora. Superar esse silêncio é emancipar o aluno ao se oferecer a ele um encontro com os obstáculos e dilemas da vida propriamente vivida, pois, como sentenciou Candido (1972, p. 84), "a literatura age com o impacto indiscriminado da própria vida e educa como ela - com altos e baixos, luzes e sombras". ${ }^{28}$

\section{REFERÊNCIAS}

BAKHTIN,M.; VOLOCHÍNOV, VN. 1929. Marxismo e Filosofia da linguagem. 16.ed. São Paulo: Hucitec Editora, 2014.

BARROS FILHO, C.; CORTELLA, M.S. Ética e vergonha na cara! Campinas: Papirus 7 Mares, 2014

BRETON, A. Manifestos do Surrealismo. Portugal: Moraes Editores, 1976.

CANDIDO, A. A literatura e a formação do homem. São Paulo: Ciência e cultura, 1972

CEREJA, W.R. Ensino de Literatura: uma proposta dialógica para trabalho com literatura. São Paulo: Atual, 2005.

COSSON, R. Letramento literário: teoria e prática. 2.ed. São Paulo: Contexto, 2006

\section{COSSON, R. Círculos de leitura e letramento literário. São} Paulo: Contexto, 2014

ENGESTRÖM, Y. 2008. Development as breaking away and opening up. Apresentação no Center for Activity Theory and Development Work Research.

FANINI, A.M.R. Embate dialógico entre leitura e escrita: manifestação de uma ética da ação discursiva a partir do Círculo bakhtiniano. Bakhtiniana, São Paulo, 10 (2): 17-35, Maio/Ago. 2015
28. CANDIDO. $A$ literatura $e$ a formacão do homem p. 74
EM TESE BELO HORIZONTE $\quad$ v. $22 \quad$ N. 3 SET.-DEz. 2016 ROLANDO. A colaboração como movimento ético-poético a caminho do [...] P. 203-218 
FERRAREZI JR.. C. Pedagogia do silenciamento: a escola brasileira e o ensino de língua materna. São Paulo: Parábola Editorial, 2014

FREIRE, P. 1967. Pedagogia do oprimido. 59.ed. Rio de Janeiro: Paz e Terra, 2015

HOLZMAN, L. Without Creating ZPDs There is No Creativity. In CONNERY, C.; JOHN-STEINER, V.; MARAJANOVIC-SHANE, A.

(Eds.). Vygotsky and Creativity. Nova York: Peter Lang Publishers, 2010. p.27-39.

JOHN-STEINER, V. Creative Collaboration. Nova York: Oxford Press, 2000

LA TAILLE, Y. A escola e os valores: a ação do professor. In: LA TAILLE, Y.; JUSTO, J.S.; PEDRO-SILVA, N. Indisciplina, disciplina: ética, moral e a ação do professor. 5.ed. Porto Alegre: Mediação, 2013. p. 5-28.

MAGALHÃES, M.C.C.;FIDALGO,S.S. The role of methodological choices in investigations conducted in school contexts: critical research on collaboration in continuing teacher education. In: RIKKA, A.; POYHONEN, S. Language in Action: Vygotsky and Leontevian legacy today. Cambridge Scholars Publishing, 2007. p. 329-351.

MAGALHÃES, M.C.C. O método para Vygotsky: a zona proxima de desenvolvimento como zona de colaboração e criticidade criativas. In: SCHETINI, R.H.; DAMIANOVIC, M.C.; SZUNDY, P.T.C. Vygotsky: uma revisita no início do século XXI. São Paulo: Andross, 2009
MAGALHÃES, M.C.C. Pesquisa critica de colaboração: escolhas epistemo-metodológicas na organização e condução de pesquisas de intervenção no contexto escolar. In: MAGALHÃES, M.C.C.; FIDALGO, S.S. (Org.). Questóes de método e de linguagem na formação docente. Campinas: Mercado das Letras, 2011, p.13-40.

MAGALHÃES, M.C.C.; OLIVEIRA, W. Vygotsky e Bakhtin/ Volochinov: dialogia e alteridade. Bakhtiniana, São Paulo, v.1 n.5, 2011, p.103-115.

MAGALHÃES, M.C.C.; OLIVEIRA, W. Argumentação na construção de contextos colaborativos em pesquisas com formação de educadores. In: LIBERALI, F.C.; DAMIANOVIC, M.C. NININ, M.O.; MATEUS, E.; GUERRA, M. (Org.). Argumentação em contexto escolar: relatos de pesquisa. Campinas: Pontes Editores, 2016. p. 205-235.

MAGALHÃES, M.C.C. Vygotsky e a pesquisa de intervenção em contexto escolar: a pesquisa crítica de colaboração - PCCOL. In: LIBERALI, F.C.; MATEUS, E.; DAMIANOVIC, M.C. A Teoria da Atividade Sócio-Histórico-Cultural e a escola: recriando realidades sociais. Campinas: Pontes Editores, 2012. p. 13-26.

MAGALHÃES, M.C.C. Escolhas teórico-metodológicas em pesquisas com formação de professores: as relações colaborativos-críticas na constituição de educadores. In: MATEUS, E.; OLIVEIRA, N.B. (Org.). Estudos crítico de linguagem e formação de professores de línguas Contribuições teórico-metodológicas. Campinas, SP: Pontes, 2014. p. 17-47 
MAGNANI, M.R.M. Leitura, Literatura e Escola: sobre a formação do gosto. 2.ed. São Paulo: Martins Fontes, 2001.

MARTINS, I. A literatura no Ensino Médio: quais os desafios do professor? In: BUNZEN, C.; MENDONÇA, M. (Org.). Português no ensino médio e formação do professor. São Paulo: Parábola Editorial, 2006. p. 83-102.

MATEUS, E. Por uma pedagogia da argumentação: In: LIBERALI, F.C.; DAMIANOVIC, M.C.; NININ, M.O.; MATEUS, E.; GUERRA, M. (Org.). Argumentação em contexto escolar: relatos de pesquisa. Campinas: Pontes Editores, 2016. p. 35-61.

NEWMAN, F.; HOLZMAN, L. 1993. Lev Vygotksy: cientista revolucionário. São Paulo: Edições Loyola, 2002.

NININ, M.O.G. Da pergunta como ato monológico avaliativo à pergunta como espaço para expansão dialógica: uma investigação à luz da linguística aplicada sobre modos de perguntar. São Carlos: Pedro e João Editores, 2013.

PAULINO, G.;COSSON,R. Letramento literário: para viver a literatura dentro e fora da escola. In: ZILBERMAN, R.;ROSING, T.M.K. Escola e leitura: velha crise, novas alternativas. São Paulo Global, 2009. p. 61-79

ROUXEL, A. Aspectos metodológicos do ensino de literatura. In DALVI, M.A.; REZENDE, N.L.; JOVER-FALEIROS, R. Leitura de literatura na escola. São Paulo: Parábola Editorial, 2013. p. 17-33

SOUZA, R.A. $\mathbf{O}$ império da eloquência: retórica e poética no Brasil Oitocentista. Rio de Janeiro: Eduerlj/Eduff, 1999.
STETSENKO, A. From Relational Ontology to Transformative Activist Stance on Development and Learning: Expanding Vygotsky's (CHAT) Project. In: JONES, P. (ed). Marxism and Education: Renewing in the Dialogue, Pedagogy and Culture. New York: Palgravve Macmillan, 2011. P. 165-192.

TIBURI, M. Filosofia prática: ética, vida cotidiana, vida virtual. 3.ed. Rio de Janeiro: Record, 2016.

VYGOTSKY, L.S. (1934). A formação social da mente. 7.ed. São Paulo: Martins Fontes: 2007

ZILBERMAN, R.; RÖSING, T.M.K. Escola e leitura: velha crise, novas alternativas. São Paulo: Global Editora, 2009.

ZINANI, C.J.A.; SANTOS, S.R.P. Ensino da literatura: pressupostos teóricos. In: ZINANI, C.J.A. (Org.). Transformando o ensino de língua e literatura: análise da realidade e propostas

metodológicas. 2.ed. Caxias do Sul: Educs, 2012. P. 13-56.
EM TESE
BELO HORIZONTE
v. 22
N. 3
SET.-DEZ. 2016
ROLANDO. A colaboração como movimento ético-poético a caminho do [...] P. 203-218

Teoria da literatura e Ensino de literatura 